\title{
Fetuin-A 742 (C/T) and 766 (C/G) polymorphic sites are associated with increased risk of myocardial infarction in older patients ( $\geq 40$ years of age)
}

\author{
AJDA COKER-GURKAN ${ }^{1}$, DENIZ COSKUN ${ }^{1}$, ELIF DAMLA ARISAN ${ }^{1}$, \\ PINAR OBAKAN $^{1}$, ÖZER SOYLU ${ }^{2}$ and NARCIN PALAVAN UNSAL ${ }^{1}$ \\ ${ }^{1}$ Department of Molecular Biology and Genetics, Istanbul Kultur University, Atakoy Campus, Istanbul 34156; \\ ${ }^{2}$ Heart and Vessel Surgery Department, Medical Park Hospital, Istanbul 34732, Turkey
}

Received March 10, 2014; Accepted December 2, 2014

DOI: $10.3892 / \mathrm{mmr} .2015 .3521$

\begin{abstract}
Inflammation and genetics have key roles in the pathogenesis of atherosclerosis, and the etiology of myocardial infarction (MI). Recent studies have indicated that lower serum levels of fetuin-A may accelerate the vascular mineralization process, which leads to pathophysiological conditions, such as coronary heart disease and chronic renal failure. The aim of the present study was to evaluate the association between specific fetuin-A polymorphisms (742 and 766) that are associated with circulating serum levels, and MI cases. The study consisted of 292 participants; 146 healthy control subjects and 146 patients with MI. The patient group was divided into two subgroups: $56 \mathrm{MI} \leq 40$ years and $90 \mathrm{MI} \geq 40$ years. The genotype distribution of fetuin $742(\mathrm{C} / \mathrm{T})$ and fetuin $766(\mathrm{C} / \mathrm{G})$ were determined by restriction enzyme digestion of polymerase chain reaction products. A significant difference was determined between the patients with $\mathrm{MI}$ and the control subjects with regards to fetuin-A $742 \mathrm{C} / \mathrm{T}$ gene polymorphism $(\mathrm{P}=0.028)$, regardless of age. Genotype distributions of fetuin-A $742(\mathrm{C} / \mathrm{G}, \mathrm{P}=0.004)$ and $766(\mathrm{C} / \mathrm{T}, \mathrm{P}=0.017)$ were statistically different in the older patients with $\mathrm{MI}$ (MI $\geq 40$ years old), as compared with the healthy controls; however, there were no significant differences between the younger patients with $\mathrm{MI}$ and the controls, with regards to fetuin- $\mathrm{A} 742 \mathrm{C} / \mathrm{T}(\mathrm{P}=0.519)$ and $766 \mathrm{C} / \mathrm{G}(\mathrm{P}=0.653)$ gene polymorphisms. In addition, an association was observed between the presence of fetuin-A $742 \mathrm{~T}$ and $766 \mathrm{G}$ alleles, and MI cases. The present study demonstrates that fetuin-A 742 $(\mathrm{C} / \mathrm{T})$ and $766(\mathrm{C} / \mathrm{G})$ genotypes may be risk factors for $\mathrm{MI}$ in patients older than 40 years of age.
\end{abstract}

Correspondence to: Dr Ajda Coker-Gurkan, Department of Molecular Biology and Genetics, Istanbul Kultur University, Atakoy Campus, MBG Building, E-5 Freeway, Istanbul 34156, Turkey

E-mail: a.coker@iku.edu.tr

Key words: fetuin-A, myocardial infarction, single nucleotide polymorphisms

\section{Introduction}

Myocardial infarction (MI) is the rapid development of myocardial necrosis, which is caused by a critical imbalance between oxygen supply and demand of the myocardium (1). MI is caused by interruption of the blood supply to the heart caused by atherosclerosis (2). Atherosclerosis is a series of consecutively developed stages that is initiated by endothelial dysfunction, followed by the generation of foam cells and fatty streaks, plaque formation, plaque rupture and thrombosis (3). A common feature of coronary atherosclerosis is intimal plaque calcification, which is followed by the generation of smooth muscle cell layer calcification. During calcification calcium $\left(\mathrm{Ca}^{2+}\right)$ and phosphate $\left(\mathrm{PO}_{4}\right)$ ions precipitate inside the coronary artery wall (4). Various calcification inhibitors, which are present in the circulating blood stream and at locally, are responsible for the prevention of mineralization. The balance between $\mathrm{Ca}^{2+}$ and $\mathrm{P}$ ions can be altered due to deficiencies of these inhibitors, leading to unwanted precipitation inside vessel walls (5). An important calcification inhibitor is fetuin-A, which acts as a central regulator extracellularly and in the circulation (6).

$\alpha-2$ Heremans Schmid glycoprotein (AHSG), also termed human fetuin, is a major serum glycoprotein that was initially identified in 1944 (7). AHSG/fetuin-A is a $46 \mathrm{kDa}$ serum glycoprotein that is commonly synthesized by hepatocytes, and consists of two polypeptide chains. Following digestion, these chains are linked by disulfide bonds (8). Until recently the exact function of this abundant serum protein remained unclear; however, there is now more knowledge regarding its multifunctional roles. Fetuin-A has been shown to remodel skeletal bones by capturing $\mathrm{Ca}^{2+}$ ions in the circulation, and depositing them in the extracellular region of bone marrow (9). Furthermore, fetuin-A inhibits the effects of insulin receptors, by auto-phosphorylation and tyrosine kinase activity destruction (10). Besides the potential effects of fetuin-A on insulin signaling, it has also been shown to hinder insulin action on adipocytes, by adiponectin production (11). Like albumin, fetuin-A is considered to be a negative acute phase reactant protein (12). In addition, it has been reported that knocking down fetuin-A (AHSG ${ }^{-/}$) expression led to organ 
calcification and myocardial dysfunction in mice transgenic models (13).

The gene that encodes fetuin-A is localized to human chromosome 3 q27 position (14), and the genomic structure consists of seven exons and six introns (15). The fetuin-A gene is highly polymorphic and various single nucleotide polymorphisms (SNPs) have been identified. One of these SNPs is a C/T alteration at the 742 position (rs4917), which leads to a missense mutation (T248 M). Another SNP within the fetuin-A gene is a $766 \mathrm{C} / \mathrm{G}$ substitution (rs4918) that results in a Thr256Ser missense mutation (16). Furthermore, it has been reported that fetuin-A serum levels are correlated with certain SNPs within the AHSG gene; and the fetuin-A 766 C/G SNP is associated with decreased circulating levels of fetuin-A (17). Previous studies have hypothesized that mortality due to cardiovascular disease and MI may be correlated with plasma levels of fetuin-A (18-20). Risk analyses have evaluated the association between fetuin-A polymorphisms and progression of MI in Western populations (21); however, further investigation is required to determine the potential role of fetuin-A (742 and 766) gene polymorphisms on MI, with regards to age, in Eastern populations. The present study aimed to determine the association between fetuin-A $742 \mathrm{C} / \mathrm{T}$ and $766 \mathrm{C} / \mathrm{G}$ polymorphisms and MI with regards to age onset.

\section{Materials and methods}

Subjects. A total of 146 patients with MI and 146 healthy controls were enrolled in the present study. MI was defined using the standard CHS criteria (22), which includes: History of chest pain, cardiac enzyme levels and characteristic changes on serial electrocardiograms. The control subjects were recruited from patients visiting the Siyami Ersek Chest, Heart and Vessel Education and Research Hospital due to chest pain or for a general health check-up. Patients with the following characteristics were excluded from the study: Pregnancy, a previous clinical history for vascular heart disease, atrial fibrillation, acute or chronic infections, immunological conditions, malignancies, neoplasm, coagulation disorders or chronic renal failure. All patients and healthy controls were informed prior to their involvement in the study.

Ethical approval. The present study was approved by the Ethics Committee of Marmara University (Istanbul, Turkey). The human rights of the subjects were protected and any necessary approval was secured from the Ethics Committee. All experiments performed on human subjects were conducted in accordance with the Declaration of Helsinki. All procedures were conducted with adequate understanding and written consent from all of the subjects.

Risk factor assessment. Age, gender and smoking habits of the subjects were obtained using a questionnaire form. Weight and height were measured, and body mass index was calculated from these measurements. Systolic and diastolic blood pressure was measured. The presence of diabetes mellitus (DM) was defined by a repeated fasting glucose level $>126 \mathrm{mg} / \mathrm{dl}$, the use of antidiabetic drugs or both. Total cholesterol, and high and low density lipoprotein cholesterol levels were determined enzymatically, and were also measured enzymatically following dextrane sulfate magnesium precipitation (23). Fibrinogen and C-reactive protein (CRP) were measured at the Biochemistry Laboratory of the Siyami Ersek Chest, Heart and Vessel Education and Research Hospital using ELISA kits [Fibronectin Human ELISA Kit, ab108847; CRP Human SimpleStep ELISA ${ }^{\mathrm{TM}}$ Kit, ab181416; Abcam, Cambridge, MA, USA] according to the manufacturer's instructions.

Genotyping. All patients and healthy controls enrolled in the present study provided 2-3 ml venous blood samples. All blood samples were added to EDTA blood collection tubes containing $1.8 \mathrm{mg} / \mathrm{ml}$ EDTA and stored at $-20^{\circ} \mathrm{C}$. Genomic DNA was then isolated from nucleated cells through harvesting using the ammonium acetate salting out method (24). Fetuin $742 \mathrm{C} / \mathrm{T}$ and $766 \mathrm{C} / \mathrm{G}$ polymorphisms were genotyped according to restriction enzyme digestions of polymerase chain reaction (PCR) products. The fetuin $742 \mathrm{C} / \mathrm{T}$ and $766 \mathrm{C} / \mathrm{G}$ genotypes were determined using PCR, followed by restriction digestion with SacI and NlaIII enzymes respectively. The following PCR primers were used: Forward: 5'-CCTCCCAAGCAGAAAC-3' and reverse: 5'-TGATGATTCCGCATACCC-3' for the Fetuin 742 region; and forward: 5'-GTCACCCCTCCTTGTAAC-3' and reverse: 5'-CCCCAATGAGACCAC-3' for fetuin including the $766 \mathrm{C} / \mathrm{G}$ SNP. All primer sequences were designed by the authors and synthesized by İontek Company localized in İstanbul Technical University Techno-Park (İstanbul, Turkey) The PCR reaction volume was $25 \mu \mathrm{l}$, containing $500 \mathrm{ng}$ DNA, $2.5 \mu \mathrm{M}$ forward and reverse primer, $0.2 \mu \mathrm{M}$ dNTP (Thermo Fisher Scientific, Waltham, MA, USA), 0.2 Units Taq DNA Polymerase (18038-042; Thermo Fisher Scientific) and $2.5 \mathrm{mM}$ of $\mathrm{MgCl}_{2}$ (Thermo Fisher Scientific). The PCR protocol included an initial denaturation step at $94^{\circ} \mathrm{C}$ for $3 \mathrm{~min}$, followed by 30 cycles of $30 \mathrm{sec}$ denaturation at $94^{\circ} \mathrm{C}$, $30 \mathrm{sec}$ annealing at $59^{\circ} \mathrm{C}$ and $45 \mathrm{sec}$ elongation at $72^{\circ} \mathrm{C}$, followed by a final elongation step at $72^{\circ} \mathrm{C}$ for $10 \mathrm{~min}$. Each $10 \mu 1$ PCR product was digested using 5 units SacI (FD1133; Thermo Fisher Scientific) and NlaIII (FD1834; Thermo Fisher Scientific) enzymes overnight at $37^{\circ} \mathrm{C}$. The digestion products were then subjected to $3 \%$ agarose gel electrophoresis.

Statistical analysis. For comparison of the groups according to MI risk factors Mann-Whitney $\mathrm{U}$ and $\chi^{2}$ tests were used. Allele and genotype frequencies among the patients with MI and the control subjects were compared with Hardy-Weinberg predictions, using Fisher $\chi^{2}$-analysis. The results were expressed as odds ratio and $95 \%$ confidence intervals. $\mathrm{P}<0.05$ ( 2 -sided) was considered to indicate a statistically significant difference. SPSS version 13.0 software (SPSS Inc., Chicago, IL, USA) was used for all statistical analyses.

\section{Results}

Clinical characteristics. The clinical characteristics of the subjects from all of the groups are presented in Table I. There was a significant difference between the patients with MI and the control subjects, with regards to gender, smoking habits, and CRP and fibrinogen levels. Fetuin-A $742 \mathrm{~T}$ allele was determined by 165 and 201 bp digestion products, whereas the $\mathrm{C}$ allele remained undigested. Fetuin-A $766 \mathrm{G}$ allele yielded 193 and 212 bp fragments, whereas the $C$ allele remained 
Table I. Baseline characteristics of the patients with MI and the control subjects.

\begin{tabular}{lcccc}
\hline Characteristic & Control $(\mathrm{n}=146)$ & MI $(\mathrm{n}=146)$ & MI $(\leq 40)(\mathrm{n}=56)$ & MI $(\geq 40)(\mathrm{n}=90)$ \\
\hline Age $($ years $)$ & $52.8 \pm 9.1$ & $54.7 \pm 9.6$ & $38.9 \pm 7.5^{\mathrm{b}}$ & $59.3 \pm 9.1$ \\
Gender $(\%)$ male & 40 & $72^{\mathrm{b}}$ & $69^{\mathrm{b}}$ & $76^{\mathrm{b}}$ \\
BMI $\left(\mathrm{kg} / \mathrm{m}^{2}\right)$ & $28.2 \pm 3.5$ & $28.5 \pm 3.8$ & $28.2 \pm 3.1$ & $28.7 \pm 3.8$ \\
SBP $(\mathrm{mmHg})$ & $132.1 \pm 17.4$ & $140.7 \pm 15.9$ & $138.5 \pm 16.1$ & $142.5 \pm 17.0$ \\
DBP (mmHg) & $78.5 \pm 12.3$ & $86.6 \pm 10.2$ & $86.4 \pm 10.1$ & $88.5 \pm 11.2$ \\
DM $(\%)$ & 10.7 & 12.7 & 12.1 & 12.9 \\
Smoker/former smoker & 23 & $51^{\mathrm{a}}$ & $48^{\mathrm{a}}$ & $52^{\mathrm{a}}$ \\
HDL (mg/dl) & $40.8 \pm 4.9$ & $42.1 \pm 4.4$ & $41.9 \pm 4.6$ & $43.1 \pm 5.2$ \\
LDL (mg/dl) & $128.7 \pm 28.3$ & $142.3 \pm 22.1$ & $203.9 \pm 32.6$ & $142.1 \pm 22.5$ \\
TC (mg/dl) & $195 \pm 37.9$ & $206.2 \pm 35.7$ & $3.2^{\mathrm{a}}$ & $208 \pm 38.2$ \\
CRP (mg/L) & 1.1 & $3.5^{\mathrm{a}}$ & $408.7 \pm 80.2^{\mathrm{a}}$ & $3.8^{\mathrm{a}}$ \\
Fibrinogen (mg/dl) & $348.8 \pm 79.2$ & $410.6 \pm 76.4^{\mathrm{a}}$ & $411.1 \pm 75.3^{\mathrm{a}}$ \\
\hline
\end{tabular}

${ }^{\mathrm{a}} \mathrm{P}<0.05$; ${ }^{\mathrm{b}} \mathrm{P}<0.001$. MI, myocardial infarction; BMI, body mass index; SBP, systolic blood pressure; DBP, diastolic blood pressure; DM, diabetes mellitus; HDL, high density lipoprotein; LDL, low density lipoprotein; TC, total cholesterol; CRP, C-reactive protein.

Table II. Genotype distribution and allele frequencies of Fetuin $742 \mathrm{C} / \mathrm{T}$ and Fetuin $766 \mathrm{C} / \mathrm{G}$ single nucleotide polymorphisms between patients with MI and control subjects.

\begin{tabular}{|c|c|c|c|c|}
\hline Variable & MI $(n=146)$ & Controls $(\mathrm{n}=146)$ & P-value & OR at $95 \% \mathrm{CI}$ \\
\hline \multicolumn{5}{|l|}{ Fetuin 742} \\
\hline $\mathrm{CC}$ & $81(55.5 \%)$ & $102(69.9 \%)$ & & \\
\hline $\mathrm{CT}$ & $57(39.0 \%)$ & $36(24.7 \%)$ & 0.028 & $0.025-0.032$ \\
\hline TT & $8(5.5 \%)$ & $8(5.5 \%)$ & & \\
\hline Allele C & 0.75 & 0.822 & 0.034 & $0.650[0.435-0.969]$ \\
\hline Allele T & 0.25 & 0.178 & & $0.810[0.685-0.976]$ \\
\hline \multicolumn{5}{|l|}{ Fetuin 766} \\
\hline $\mathrm{CC}$ & $80(54.8 \%)$ & $95(65.1 \%)$ & & \\
\hline CG & $58(39.7 \%)$ & $43(29.5 \%)$ & 0.172 & $0.169-0.184$ \\
\hline GG & $8(5.5 \%)$ & $8(5.5 \%)$ & & \\
\hline Allele C & 0.747 & 0.798 & 0.139 & $0.868[0.726-1.039]$ \\
\hline Allele G & 0.253 & 0.202 & & $0.746[0.506-1.101]$ \\
\hline
\end{tabular}

MI, myocardial infarction; OR, odds ratio; CI, confidence interval.

undigested by SacI restriction enzyme (Fig. 1). The genotype distributions and allele frequencies of fetuin-A $742 \mathrm{C} / \mathrm{T}$ and $766 \mathrm{C} / \mathrm{G}$ SNPs within the MI and control groups are presented in Table II. Only fetuin-A $742 \mathrm{C} / \mathrm{T}$ genotype distribution was significantly different between the MI and control groups $(\mathrm{P}=0.028)$. Conversely, there was no significant difference between the genotype distribution of fetuin-A $766 \mathrm{C} / \mathrm{G}$ in the $\mathrm{MI}$ and control groups ( $\mathrm{P}=0.172)$. The fetuin-A 742 and 766 alleles were compared between the MI and control subjects, and only the $742 \mathrm{C}$ allele was shown to be associated with a high risk of $\mathrm{MI}(\mathrm{P}=0.034$; Table II).

Distribution of polymorphisms between patient groups. The present study also investigated the distribution of the polymorphic sites between subgroups of the MI group, as compared with the control group. The most significant subgroup was age-related case distribution. A cut-off value of 40 years old was applied to the MI group, and the patients were divided into two groups: $\mathrm{MI} \leq 40$ years old or $\mathrm{MI} \geq 40$ years old. The genotype distributions and allele frequencies of fetuin-A 742 and 766 gene polymorphisms in the younger and older MI groups and the healthy controls are presented in Table III and IV. Neither fetuin-A 742 C/T ( $\mathrm{P}=0.519)$ nor fetuin-A 766 C/G (P=0.653) genotype distributions were significantly different between the young patients with MI and the healthy control subjects. Similar to this result, the allele frequencies of fetuin-A [742 $(\mathrm{C} / \mathrm{T})$ and $766(\mathrm{G} / \mathrm{C})$ ] were not significantly different between the young patients with $\mathrm{MI}$ and the control subjects $(\mathrm{P}=0.259$ 
Table III. Genotype distribution and allele frequencies of Fetuin $742 \mathrm{C} / \mathrm{T}$ and $766 \mathrm{C} / \mathrm{G}$ single nucleotide polymorphisms between young patients with MI and control subjects.

\begin{tabular}{lcccc}
\hline Variable & MI $\leq 40(\mathrm{n}=56)$ & Controls $(\mathrm{n}=146)$ & P-value & OR at 95\% CI \\
\hline Fetuin 742 & & & & \\
CC & $35(62.5 \%)$ & $102(69.9 \%)$ & 0.519 & $0.508-0.528$ \\
CT & $16(28.6 \%)$ & $36(24.7 \%)$ & & 0.259 \\
TT & $5(8.9 \%)$ & $8(5.5 \%)$ & & $0.719[0.550-1.137]$ \\
Allele C & 0.768 & 0.822 & & $0.716[0.422-1.219]$ \\
Allele T & 0.232 & 0.178 & 0.653 & \\
Fetuin 766 & $36(64.3 \%)$ & $95(65.1 \%)$ & & $0.672-0.690$ \\
CC & $15(26.8 \%)$ & $43(29.5 \%)$ & 0.639 & $0.919[0.628-1.328]$ \\
CG & $5(8.9 \%)$ & $8(5.5 \%)$ & & $0.882[0.519-1.495]$ \\
GG & 0.777 & 0.798 & 0.202 & \\
Allele C & 0.223 & & & \\
Allele G & &
\end{tabular}

MI, myocardial infarction; OR, odds ratio; CI, confidence interval.

Table IV. Genotype distributions and allele frequencies of Fetuin $742 \mathrm{C} / \mathrm{T}$ and $766 \mathrm{C} / \mathrm{G}$ single nucleotide polymorphisms between older patients with MI and control subjects.

\begin{tabular}{|c|c|c|c|c|}
\hline Variable & $M I \geq 40(n=90)$ & Controls ( $\mathrm{n}=146)$ & P-value & OR at $95 \% \mathrm{CI}$ \\
\hline \multicolumn{5}{|l|}{ Fetuin 742} \\
\hline $\mathrm{CC}$ & $46(51.1 \%)$ & $102(69.9 \%)$ & & \\
\hline $\mathrm{CT}$ & $41(45.6 \%)$ & $36(24.7 \%)$ & 0.004 & $0.002-0.005$ \\
\hline $\mathrm{TT}$ & $3(3.3 \%)$ & $8(5.5 \%)$ & & \\
\hline Allele C & 0.738 & 0.822 & 0.036 & $0.752[0.586-0.963]$ \\
\hline Allele $\mathrm{T}$ & 0.262 & 0.178 & & $0.613[0.392-0.962]$ \\
\hline \multicolumn{5}{|l|}{ Fetuin 766} \\
\hline $\mathrm{CC}$ & $44(48.9 \%)$ & $95(65.1 \%)$ & & \\
\hline $\mathrm{CG}$ & $43(47.8 \%)$ & $43(29.5 \%)$ & 0.017 & $0.012-0.017$ \\
\hline GG & $3(3.3 \%)$ & $8(5.5 \%)$ & & \\
\hline Allele C & 0.728 & 0.798 & 0.078 & $0.793[0.618-1.017]$ \\
\hline Allele $\mathrm{G}$ & 0.272 & 0.202 & & $0.677[0.433-1.046]$ \\
\hline
\end{tabular}

MI, myocardial infarction; OR, odds ratio; CI, confidence interval.

and 0.639, respectively; Table III). However, fetuin-A (742 and 766) gene polymorphisms had a significantly increased presence in the older patients with $\mathrm{MI}$, as compared with control subjects $(\mathrm{P}=0.004$ and $\mathrm{P}=0.017$, respectively). However, in the older patient subgroup, fetuin-A $742(\mathrm{C} / \mathrm{T})$ allele frequency was significantly higher, as compared with the control group $(\mathrm{P}=0.036)$, yet fetuin-A $766(\mathrm{C} / \mathrm{T})$ was not $(\mathrm{P}=0.078$; Table IV).

Carrier status for the $\mathrm{C}$ allele at exon 6 or 7 of fetuin-A 742 or 766 respectively was associated with susceptibility to MI [allele carrier frequencies; $\mathrm{MI}=57.5 \%$, controls $=77.4 \%$ $(\mathrm{P}=0.0003)]$. The lack of two $\mathrm{C}$ alleles in the fetuin-A gene was significantly more likely in the older patients with $\mathrm{MI}$. However, the absence of $\mathrm{C}$ alleles was shown to increase the risk of $\mathrm{MI}$ at a young age $(\mathrm{OR}=1.902,95 \% \mathrm{CI}=0.998-2.444$, $\mathrm{P}=0.0579$ ).

\section{Discussion}

Cardiovascular disease (CVD) is the most common cause of mortality worldwide (25). Although CVD-associated mortality rates have declined in Western countries due to preventative strategies, there are increasing numbers of high-risk groups for CVD in developing countries (26). There are various clinical outcomes of CVD, such as stroke, angina pectoris and MI. CVD is a multifactorial polygenic disease that is controlled by genetic and environmental risk factors (26). According to various case-control studies, age, gender (male), smoking, family history, obesity, hypertension and DM are all known risk factors for MI (27).

The etiology of MI is atherosclerosis of the coronary arteries. Atherosclerosis is a chronic inflammatory disease of 
Table V. Concominant carrier status of Fetuin $742 \mathrm{C}$ and $766 \mathrm{C}$ alleles in patients with MI.

\begin{tabular}{lrr}
\hline Allele T $(742)+$ Allele G (766) & Carriers $(\%)$ & Non-carriers $(\%)$ \\
\hline Panel A & & $62(42.5)$ \\
MI patients (n=146) & $84(57.5)$ & $33(22.6)$ \\
Controls $(\mathrm{n}=146)$ & $113(77.4)$ & \\
Panel B & & $20(35.7)$ \\
MI at $\leq 40$ years old $(\mathrm{n}=56)$ & $36(64.3)$ & $33(22.6)$ \\
Controls (n=146) & $113(77.4)$ & \\
Panel C & $48(53.3)$ & $42(46.7)$ \\
MI at $\geq 40$ years old $(\mathrm{n}=90)$ & $113(77.4)$ & $33(22.6)$ \\
Controls $(\mathrm{n}=146)$ &
\end{tabular}

Panel A represents the statistical analysis (allele frequencies) fetuin 742 and fetuin $766 \mathrm{C}$ carrier vs. $\mathrm{C}$ non-carriers: $\chi^{2}=13.12, \mathrm{df}=1, \mathrm{P}=0.0003$; RR-1.531; [95\% CI: (1.230-1.905)], OR=2.527; [95\% CI=(1.521-4.201)]. Panel B represents the statistical analysis (allele frequencies) fetuin 742 and fetuin $766 \mathrm{C}$ carrier vs. $\mathrm{C}$ non-carriers: $\chi^{2}=3.595, \mathrm{df}=1, \mathrm{P}=0.0579 ; \mathrm{RR}=1.562 ;[95 \% \mathrm{CI}=(0.9980-2.444)], \mathrm{OR}=1.902 ;[95 \%$ $\mathrm{CI}=(0.9731-3.719)]$. Panel $\mathrm{C}$ represents the statistical analysis (allele frequencies) fetuin 742 and fetuin $766 \mathrm{C}$ carrier vs. $\mathrm{C}$ non-carriers: $\chi^{2}=14.87, \mathrm{df}=1, \mathrm{P}=0.0001 ; \mathrm{RR}=1.878 ;[95 \% \mathrm{CI}=(1.377-2.562)], \mathrm{OR}=2.996 ;$ [95\% $\left.\mathrm{CI}=(1.699-5.285)\right] \mathrm{CI}$, confidence interval.
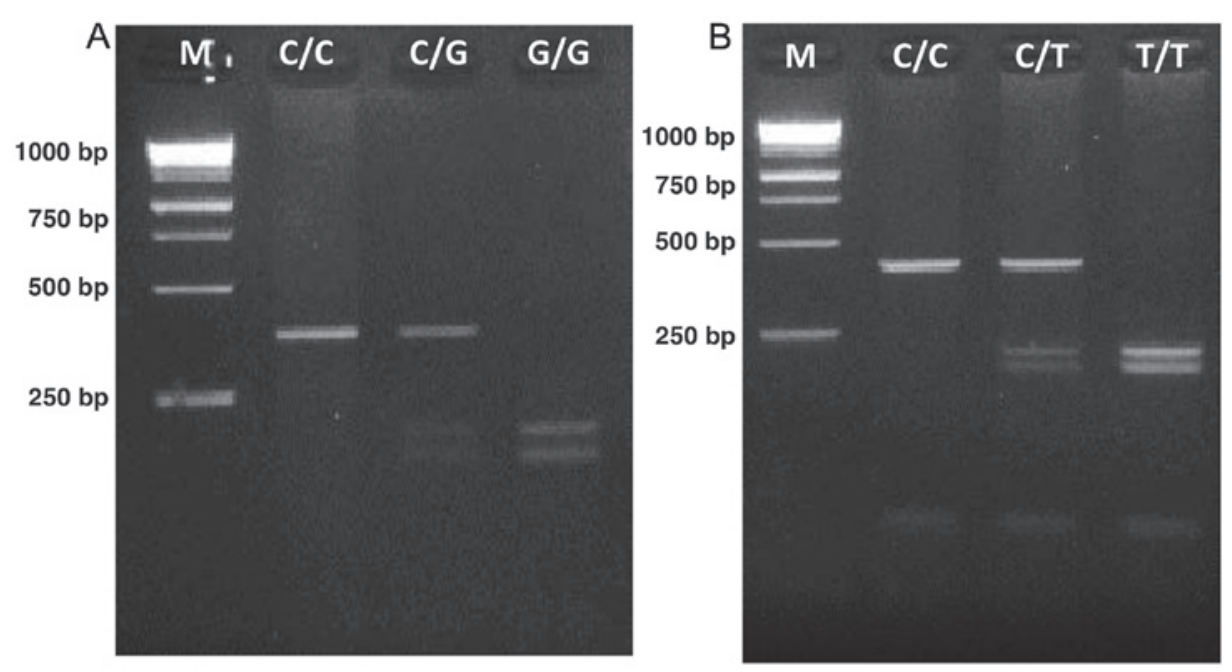

Figure 1. Genotyping of fetuin-A polymorphisms. (A) Genotyping of fetuin-A ( $+766 \mathrm{C} / \mathrm{G})$ gene polymorphism. M, 1 kb DNA Marker; lane 2, homozygous for allele C (405 bp); lane 3, heterozygous for allele C and allele $\mathrm{G}$ (405 bp, $212 \mathrm{bp}$ and $193 \mathrm{bp}$ ); lane 4, homozygous for allele G (212 bp and 193 bp). (B) Genotyping of fetuin-A (+742 C/T) gene polymorphism. Lane $1(\mathrm{M}), 1 \mathrm{~kb}$ DNA Marker; lane 2, homozygous for allele C (366 bp); lane 3, is heterozygous for allele C and allele T (366 bp, 201 bp and 165 bp); lane 4, homozygous for allele T (201 bp and 165 bp).

the arterial wall that is characterized by an accumulation of inflammatory cytokines and cells, which migrate across the arterial wall. Migration of various inflammatory cells, such as T-lymphocytes and macrophages, into the intermediate layer of the artery wall due to epithelial dysfunction, occurs in the initiation of atherosclerosis (3). Following cell migration the cells, particularly macrophages, engulf oxidized LDL and become foam cells. An accumulation of foam cells and activation of inflammatory cells leads to the release of pro-inflammatory cytokines, such as interleukin (IL)-1 and tumor necrosis factor (TNF), which leads to plaque formation (28). Plaque enlargement through the artery lumen causes shear stress and plaque instability (29). Plaque diameter, localization on the artery as well as plaque rupture or thrombosis may result in clinical symptoms, including coronary artery disease, angina pectoris or MI (30). According to coronary angiographic morphologies coronary artery plaque lesions can be classified into four types: Concentric, type I eccentric, type II eccentric and multiple irregular lesions. Among these categories, type II eccentric lesions are clinically detected in angina pectoris and MI (31). Doherty et al (32), suggested that coronary artery calcification, a major result of $\mathrm{Ca}^{2+}$ ion deposits within the coronary artery wall, is a protective process against the rupture of vulnerable plaques. Non- or mildly-calcified coronary arteries are observed in MI, whereas extremely calcified plaques are generally observed in cases of stable angina. The amount of coronary calcification has been shown to increase with age, and is more common in males of all ages (33). According to previous electron-beam computed tomography results, coronary artery plaque calcification was reported as an important scale for MI progression (34). The clinical outcome of $\mathrm{MI}$ is determined according to degree and time course of obstruction, collateral blood flow, and myocardial 
oxygen demand following thrombosis of the disrupted coronary plaques; however, coronary artery calcification is the most common symptom of MI regardless of age and gender (35).

Fetuin-A is a circulating protein that inhibits calcification by binding $\mathrm{CaXPO}_{4}$ ions and preventing precipitation (36). Knock out of fetuin-A expression in mice led to vascular calcification, due to increased transforming growth factor- $\beta$, collagen and fibronectin expression levels in cardiac cells (37). In vivo fetuin-A has been shown to induce the expression of pro-inflammatory cytokines, including IL-6 and TNF, in adipose tissues when liver fat accumulation has been observed (38). Furthermore, increased fetuin-A expression was previously shown to cause insulin resistance by suppressing insulin receptor autophosphorylation and tyrosine kinase activity (10). Fetuin-A is associated with various metabolic syndromes, including atherosclerosis. The role of fetuin-A on atherosclerosis is suggested to be linked with the deactivation of macrophages, by inhibition of pro-inflammatory cytokine expression, due to its $\mathrm{Ca}^{2+}$ binding potential (2). Therefore, the association between plasma fetuin-A levels and MI risk has been investigated in certain studies (36). However, contradictory results have been obtained from these studies. Ketteler et al (39) demonstrated that low levels of plasma fetuin-A were correlated with cardiovascular-associated mortality in hemodialysis patients. Furthermore, low fetuin-A levels were shown to be linked with mitral and aortic calcification and stenosis, in Western European countries (18-21,40-42). In the Turkish population, decreased fetuin-A levels were determined in patients with acute coronary syndrome, as compared with healthy controls (42). Conversely, coronary artery calcification has been shown to be associated with increased plasma fetuin-A levels in diabetic nephropathy (19). Increased plasma levels of fetuin-A were also established in patients with MI, regardless of MI-associated risk factors, such as age, smoking habit and CRP levels (18). In addition, fetuin-A has been indicated as a predictor of mortality, in ST-elevated MI cases (20). These results suggest that serum plasma fetuin-A levels may be a predictor of coronary artery calcification, or MI-associated mortality. As serum protein levels may differ according to disease stage, time of measurement or other metabolic syndrome involvement, investigation of the association between MI and fetuin-A levels may be a potential diagnostic tool. Fetuin-A is encoded by the ASHG gene localized at the $3 \mathrm{q} 27$ chromosome region, and is highly polymorphic $(14,15)$. A total of 30 SNPs have been identified in the fetuin-A gene, and the most frequently observed SNPs that are linked with fetuin-A levels were $742 \mathrm{C} / \mathrm{T}$ and $766 \mathrm{C} / \mathrm{G}$ SNPs (16). It has previously been reported that fetuin-A 766 Ser allele carriers have lower fetuin-A levels, as compared with Thr allele carriers (17). Recently, the EPIC-Postdam study showed that fetuin-A 742 C (rs4917) allele is associated with high plasma fetuin-A levels and MI risk (21). According to these findings, although fetuin-A SNPs may determine fetuin-A plasma levels, the levels could also change due to renal disease, diabetes mellitus or ethnic origin. Instead of measuring fetuin-A plasma levels in MI risk determination, SNPs within the fetuin-A gene may have potential in the determination of MI risk. The present study determined that fetuin-A $742 \mathrm{C} / \mathrm{T}$ and $766 \mathrm{C} / \mathrm{G}$ genotypes were associated with MI in older patients. The results of the present study demonstrated that fetuin-A $742 \mathrm{~T}$ allele is linked with MI susceptibility and older patients with MI were more likely to carry both $742 \mathrm{~T}$ and $766 \mathrm{G}$ alleles. This is the first report, to the best of out knowledge, to demonstrate that carriage of two alleles in both fetuin-A $742 \mathrm{C} / \mathrm{T}$ and $766 \mathrm{C} / \mathrm{G}$ SNPs may be a genetic marker for the susceptibility to $\mathrm{MI}$ at an older age.

\section{Acknowledgements}

The present study was supported by the Istanbul Kultur University Research Fund.

\section{References}

1. Pouleur AC, Barkoudah E, Uno H, et al: Pathogenesis of sudden unexpected death in a clinical trial of patients with myocardial infarction and left ventricular dysfunction, heart failure, or both. Circulation 122: 597-602, 2010.

2. Wang H and Eitzman DT: Acute myocardial infarction leads to acceleration of atherosclerosis. Atherosclerosis 229: 18-22, 2013.

3. Ross R: Atherosclerosis is an inflammatory disease. Am Heart J 138: 419-420, 1999.

4. Hong C, Zhu F, Du D, Pilgram TK, Sicard GA and Bae KT: Coronary artery calcification and risk factors for atherosclerosis in patients with venous thromboembolism. Atherosclerosis 183: $169-174,2005$

5. McGeachie M, Ramoni RL, Mychaleckyj JC, et al: Integrative predictive model of coronary artery calcification in atherosclerosis. Circulation 120: 2448-2454, 2009.

6. Westenfeld R, Schäfer C, Smeets R, et al: Fetuin-A (AHSG) prevents extraosseous calcification induced by uraemia and phosphate challenge in mice. Nephrol Dial Transplant 22: 1537-1546, 2007.

7. Anderson L and Anderson NG: High resolution two-dimensional electrophoresis of human plasma proteins. Proc Natl Acad Sci USA 74: 5421-5425, 1977 .

8. Lee CC, Bowman BH and Yang FM: Human alpha 2-HS-glycoprotein: the A and B chains with a connecting sequence are encoded by a single mRNA transcript. Proc Natl Acad Sci USA 84: 4403-4407, 1987.

9. Jahnen-Dechent W, Schinke T, Trindl A, et al: Cloning and targeted deletion of the mouse fetuin gene. J Biol Chem 272: 31496-31503, 1997.

10. Auberger P, Falquerho L, Contreres JO, et al: Characterization of a natural inhibitor of the insulin receptor tyrosine kinase: cDNA cloning, purification and anti-mitogenic activity. Cell 58: 631-640, 1989 .

11. DahlmanI,ErikssonP,KaamanM,etal:alpha2-Heremans-Schmid glycoprotein gene polymorphisms are associated with adipocyte insulin action. Diabetologia 47: 1974-1979, 2004

12. Lebreton JP, Joisel F, Raoult JP, Lannuzel B, Rogez JP and Humbert G: Serum concentration of human alpha 2 HS glycoprotein during the inflammatory process: evidence that alpha 2 HS glycoprotein is a negative acute-phase reactant. J Clin Invest 64: 1118-1129, 1979.

13. Schafer C, Heiss A, Schwarz A, et al: The serum protein alpha 2-Heremans-Schmid glycoprotein/fetuin-A is a systemically acting inhibitor of ectopic calcification. J Clin Invest 112: 357-366, 2003.

14. Rizzu P and Baldini A: Three members of the human cystatin gene superfamily, AHSG, HRG and KNG, map within one megabase of genomic DNA at 3q27. Cytogenet Cell Genet 70: 26-28, 1995.

15. Osawa M, Umetsu K, Sato M, et al: Structure of the gene encoding human alpha 2-HS glycoprotein (AHSG). Gene 196: 121-125, 1997.

16. Osawa M, Yuasa I, Kitano T, et al: Haplotype analysis of the human alpha2-HS glycoprotein (fetuin) gene. Ann Hum Genet 65: 27-34, 2001.

17. Stenvinkel P, Pecoits-Filho R, Lindholm B and DialGene C: Gene polymorphism association studies in dialysis: the nutrition-inflammation axis. Semin Dial 18: 322-330, 2005.

18. Weikert C, Stefan N, Schulze MB, et al: Plasma fetuin-a levels and the risk of myocardial infarction and ischemic stroke. Circulation 118: 2555-2562, 2008. 
19. Mehrotra R, Westenfeld R, Christenson P, et al: Serum fetuin-A in nondialyzed patients with diabetic nephropathy: relationship with coronary artery calcification. Kidney Int 67: 1070-1077, 2005.

20. Lim P, Collet JP, Moutereau S, et al: Fetuin-A is an independent predictor of death after ST-elevation myocardial infarction. Clin Chem 53: 1835-1840, 2007.

21. Fisher E, Stefan N, Saar K, et al: Association of AHSG gene polymorphisms with fetuin-A plasma levels and cardiovascular diseases in the EPIC-Potsdam study. Circ Cardiovasc Genet 2: 607-613, 2009

22. Fried LP, Borhani NO, Enright P, et al: The cardiovascular health study: design and rationale. Ann Epidemiol 1:263-276, 1991.

23. Friedewald WT, Levy RI and Fredrickson DS: Estimation of the concentration of low-density lipoprotein cholesterol in plasma, without use of the preparative ultracentrifuge. Clin Chem 18: 499-502, 1972

24. Chen W: Rapid isolation of DNA from human peripheral blood. Zhongguo Yi Xue Ke Xue Yuan Xue Bao 14: 141-142, 1992 (In Chinese)

25. Murray CJ and Lopez AD: Evidence-based health policy-lessons from the global burden of disease study. Science 274: 740-743, 1996

26. Yusuf S, Reddy S, Ounpuu S and Anand S: Global burden of cardiovascular diseases: part I: general considerations, the epidemiologic transition, risk factors and impact of urbanization. Circulation 104: 2746-2753, 2001

27. Wilson PW, D'Agostino RB, Levy D, Belanger AM, Silbershatz H and Kannel WB: Prediction of coronary heart disease using risk factor categories. Circulation 97: 1837-1847, 1998.

28. Maseri A and Fuster V: Is there a vulnerable plaque? Circulation 107: 2068-2071, 2003

29. Holmes DR Jr, Hartzler GO, Smith HC and Fuster V: Coronary artery thrombosis in patients with unstable angina. Br Heart J 45: 411-416, 1981.

30. Mandelkorn JB, Wolf NM, Singh S, et al: Intracoronary thrombus in nontransmural myocardial infarction and in unstable angina pectoris. Am J Cardiol 52: 1-6, 1983.

31. Ambrose JA, Winters SL, Arora RR, et al: Coronary angiographic morphology in myocardial infarction: a link between the pathogenesis of unstable angina and myocardial infarction. J Am Coll Cardiol 6: 1233-1238, 1985.

32. Doherty TM, Detrano RC, Mautner SL, Mautner GC and Shavelle RM: Coronary calcium: the good, the bad and the uncertain. Am Heart J 137: 806-814, 1999.
33. Shemesh J, Stroh CI, Tenenbaum A, et al: Comparison of coronary calcium in stable angina pectoris and in first acute myocardial infarction utilizing double helical computerized tomography. Am J Cardiol 81: 271-275, 1998.

34. Raggi P, Cooil B, Shaw LJ, et al: Progression of coronary calcium on serial electron beam tomographic scanning is greater in patients with future myocardial infarction. Am J Cardiol 92: 827-829, 2003

35. Vliegenthart R, Oudkerk M, Song B, van der Kuip DA, Hofman A and Witteman JC: Coronary calcification detected by electron-beam computed tomography and myocardial infarction. The rotterdam coronary calcification study. Eur Heart J 23: 1596-1603, 2002.

36. Schinke T, Amendt C, Trindl A, Pöpschke O, Müller-Esterl W and Jahnen-Dechent W: The serum protein alpha2-HS glycoprotein/fetuin inhibits apatite formation in vitro and in mineralizing calvaria cells. A possible role in mineralization and calcium homeostasis. J Biol Chem 271: 20789-20796, 1996.

37. Merx MW, Schäfer C, Westenfeld R, et al: Myocardial stiffness, cardiac remodeling and diastolic dysfunction in calcification-prone fetuin-A-deficient mice. J Am Soc Nephrol 16: 3357-3364, 2005.

38. Stefan N,Hennige AM,StaigerH, etal: Alpha2-Heremans-Schmid glycoprotein/fetuin-A is associated with insulin resistance and fat accumulation in the liver in humans. Diabetes Care 29: 853-857, 2006.

39. Ketteler M, Bongartz P, Westenfeld R, et al: Association of low fetuin-A (AHSG) concentrations in serum with cardiovascular mortality in patients on dialysis: a cross-sectional study. Lancet 361: 827-833, 2003.

40. Kaden JJ, Reinöhl JO, Blesch B, et al: Systemic and local levels of fetuin-A in calcific aortic valve stenosis. Int J Mol Med 20: 193-197, 2007.

41. Ix JH, Chertow GM, Shlipak MG, Brandenburg VM, Ketteler M and Whooley MA: Association of fetuin-A with mitral annular calcification and aortic stenosis among persons with coronary heart disease: data from the Heart and Soul Study. Circulation 115: 2533-2539, 2007.

42. Afsar CU, Uzun H, Yurdakul S, et al: Association of serum fetuin-A levels with heart valve calcification and other biomarkers of inflammation among persons with acute coronary syndrome. Clin Invest Med 35: E206-E215, 2012. 